\title{
СТРОИТЕЛЬСТВО И ОКРУЖАЮЩАЯ СРЕДА - ПОВЫШЕНИЕ ЭНЕРГОЭФФЕКТИВНОСТИ
}

Баснукаев И.Ш., Мовсулов М.М. ГГНТУ им. академика Миллионщикова, г. Грозный

Экологически чистые строительные материаль включают нетоксичные материаль и предметы интерьера, материаль из вторичного сырья или использованные материалы, а также древесину и другие материаль из возобновляемых источников. Внедрение ресурсо- и энергосбережения в строительстве требует внесения изменений в технологические процессы, но также и в нормативные акты и техническую документацию на всех уровнях управления. В данной статье рассматриваются сущность и основные направления ресурсо- энергосбережения в строительной отрасли России. Важнейшим элементом зеленого строительства является энергоэффективность. Более высокий уровень энергоэффективность снижает выбросы углерода - как от электростанций, так и от собственных энергетических систем дома.

Ключевые слова: зеленое строительство, энергоэффективность, энергосбережение, энергоёмкость, окружающая среда, экология.

Важнейшим элементом зеленого строительства является энергоэффективность. Более высокий уровень энергоэффективность снижает выбросы углерода - как от электростанций, так и от собственных энергетических систем дома. Проекты с высокой плотностью застройки и заполнением (используя свободные объекты, такие как автостоянки, торговые центры и фабрики) снижают общую экологическую нагрузку дома. Места с доступом к общественному транспорту или в нескольких минутах ходьбы от магазинов и школ помогают снизить потребление энергии и загрязняющих веществ. Небольшие дома потребляют меньше энергии и меньше строительных материалов, а умные конструкции зданий максимизируют выгоду от солнечного света и дневного освещения, одновременно снижая потребление энергии за счет эффективного озеленения и затенения. Экологически чистые строительные материалы включают нетоксичные материалы и предметы интерьера, материалы из вторичного сырья или использованные материалы, а также древесину и другие материалы из возобновляемых источников. Использование экологически чистых строительных материалов может помочь обеспечить здоровую внутреннюю среду, одновременно уменьшая общее воздействие на окружающую среду дома. Тщательный дизайн и планирование, в сочетании с использованием сборных компонентов, могут помочь уменьшить количество строительного мусора, который в противном 
случае пришлось бы утилизировать, часто на свалках или при сжигании. Зеленые дома также помогают сохранить один из наших самых важных ресурсов - воду. Такие функции, как водосберегающие ирригационные системы, уменьшенный размер участка и ландшафтный дизайн с низким водопользованием, а также водосберегающие внутренние светильники - все это способствует общей эффективности использования воды. Использование нетоксичных материалов в сочетании $\mathrm{c}$ естественной вентиляцией и эффективной фильтрацией воздуха может помочь улучшить качество воздуха в помещении, контролировать уровень влажности в помещении и защитить жителей от плесени, химикатов, побочных продуктов сгорания и других загрязнителей в помещении.

Энергоэффективность - это показатель, являющийся обратным энергоемкости. Энергоэффективность определяет количество строительной продукции, произведённое при затрате строительной компанией условной единицы топливно-энергетических ресурсов. По мнению Б.И. Врублевского энергоэффективность - это «научно обоснованная абсолютная или удельная величина потребления топливно-энергетических ресурсов на производство единицы продукции» [1].

Формула для расчета энергоэффективности:

$$
\ni_{\ni}=\frac{\Pi}{T+T_{T} \times k_{1}+T_{\text {эл }} \times k_{2}}
$$

где П - объем выпуска продукции в рублях

Т - количество потребляемого топлива, т.у.т.

$\mathrm{T}_{\mathrm{T}}-$ количество потребляемой тепловой энергии, Гкал

$\mathrm{T}_{\text {эл }}-$ количество потребляемой электроэнергии, кВт·ч

$\mathrm{k}_{1}$ и $\mathrm{k}_{2}$ - коэффициенты, обеспечивающие перевод тепловой и электрической энергии в т.у.т. [4]

Следующим этапом комплексной оценки энергозатрат является расчет ресурсных и энергетических потоков, который включает в себя:

- исследование направленности ресурсных и энергетических потоков на предприятии;

- установление наиболее крупных потребителей материалов и энергии;

- выявление удельного веса потребления каждого ресурса по ключевым потребителям с разработкой их ресурсных и энергетических балансов.

После анализа объёмов потребления ресурсов определяются направления оптимизации затрат на промышленном предприятии.

В строительном секторе ресурсосбережение и энергосбережение базируется не только на анализе потребления ресурсов, но и на исследовании факторов, влияющих на их модификацию. Классификация факторов, оказывающих влияние на затраты ресурсов строительного предприятия, строится на нескольких подходах. Используя анализ позиций различных исследователей, можно разработать собственный подход к классификации указанных факторов в сфере строительства (рис.1). 


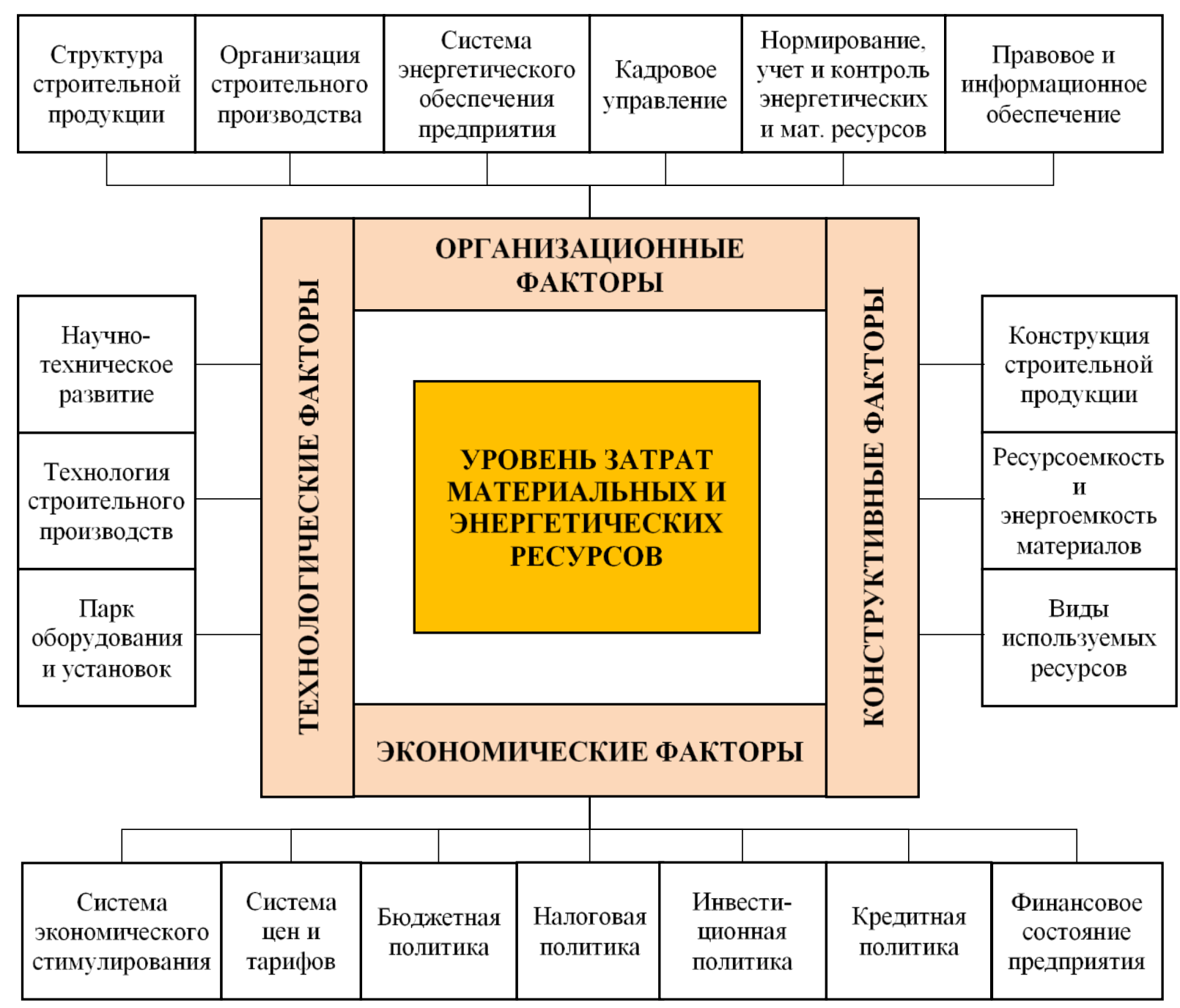

Рис.1 Разработка системы факторов, влияющих на уровень затрат материальных и топливно-энергетических ресурсов строительного предприятия Источник: Максимчук О.В. Управление энергоэффективностью: Учебник / О.В. Максимчук, Т.А. Першина. - Волгоград : ВолгГАСУ, 2014.

Механизмы и технологии ресурсо- и строительного промышленного предприятия разрабатываются по четырем группам факторов энергосбережения: организационным, экономическим, технологическим и конструктивным [3].

Мероприятия по оптимизации затрат топливно-энергетических ресурсов с использованием организационных факторов воздействия представлены на рис.2. 


\begin{tabular}{|c|c|c|}
\hline \multirow{6}{*}{ 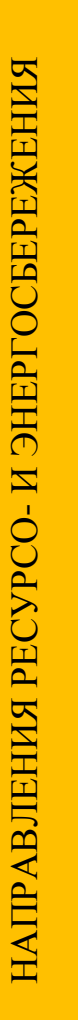 } & $\begin{array}{l}\text { Организация } \\
\text { производства }\end{array}$ & $\begin{array}{l}\text { Использование инновационных материалов, } \\
\text { возобновляемых источников энергии и вторичных } \\
\text { энергоресурсов, автоматизация }\end{array}$ \\
\hline & $\begin{array}{l}\text { Кадровое } \\
\text { управление }\end{array}$ & $\begin{array}{l}\text { Укрепление трудовой дисциплины, повышение } \\
\text { квалификации работников, стимулирование } \\
\text { сбережения }\end{array}$ \\
\hline & $\begin{array}{l}\text { Нормирование, } \\
\text { учет и контроль } \\
\text { энергетических } \\
\text { nесvnсов } \\
\end{array}$ & $\begin{array}{l}\text { Разработка обоснованных норм, создание } \\
\text { эффективной системы учета энергозатрат и } \\
\text { ресурсного и энергоаудита с выявлением причин } \\
\text { отклонений }\end{array}$ \\
\hline & $\begin{array}{c}\text { Технология } \\
\text { изготовления }\end{array}$ & $\begin{array}{l}\text { Внедрение высокоэффективных } \\
\text { ресурсосберегающих технологий }\end{array}$ \\
\hline & $\begin{array}{c}\text { Парк оборудования } \\
\text { и установок }\end{array}$ & $\begin{array}{l}\text { Рост доли инновационного и энергоэффективного } \\
\text { оборудования, организация своевременных ремонтов } \\
\text { для предотвращения аварий и простоев }\end{array}$ \\
\hline & $\begin{array}{l}\text { Финансовое } \\
\text { состояние }\end{array}$ & $\begin{array}{l}\text { Улучшение финансового состояния } \rightarrow \\
\text { Высвобождение дополнительных ресурсов для } \\
\text { совершенствования технологии и энергосбережения }\end{array}$ \\
\hline
\end{tabular}

Рис.2 Организационные механизмы снижения энергозатрат промышленного предприятия

Источник: Основы энергосбережения: учебное пособие / Под. ред. Б.И. Врублевского. Гомель: ЧУП «ЦНТУ «Развитие», 2017.

Реализация перечисленных мероприятий на макроуровне и на уровне отдельных строительных предприятий будет способствовать оптимизации энергозатрат на уровне отдельных экономических субъектов, региона, отрасли и национального хозяйства в целом.

В рамках данного исследования мы выделили четыре группы факторов, оказывающих непосредственное влияние на уровень энергозатрат строительного предприятия: организационные, экономические, технологические и конструктивные. Таким образом, создание механизмов энергосбережения должна осуществляться комплексно по всем направлениям работы строительного предприятия. Это позволит получить эффективное ресурсо- и энергосбережение и, как следствие, обеспечить повышение прибыли и конкурентоспособности строительного предприятия.

\section{Исследование выполнено при финансовой поддержке РФФИ в рамках научного проекта № 18-48-200001.}




\section{Список литературы}

1. Максимчук О.В. Управление энергоэффективностью: Учебник / О.В. Максимчук, Т.А. Першина. - Волгоград: ВолгГАСУ, 2014.

2. Основы энергосбережения: учебное пособие / Под. ред. Б.И. Врублевского. - Гомель: ЧУП «ЦНТУ «Развитие», 2017.

3. Харитонов В.А. Основы организации и управления в строительстве: учебник / В.А. Харитонов. -М.: Издательский центр «Академия», 2013 [1]

4. Шеметов А.Н. Энергетический аудит: организация, методология, технология / А. Н. Шеметов. - Магнитогорск: ФГБОУ ВПО «МГТУ», 2016. 